\title{
Effects of a neonicotinoid pesticide on thermoregulation of African honey bees (Apis mellifera scutellata)
}

Simone Tosi ${ }^{\mathrm{a}, \mathrm{b}, \mathrm{c}, 1}$, Fabien J. Démares ${ }^{\mathrm{d}, 1}$, Susan W. Nicolson ${ }^{\mathrm{d}}$, Piotr Medrzycki ${ }^{\mathrm{b}}$, Christian W.W. Pirk ${ }^{\mathrm{d}}$ and Hannelie Human ${ }^{\mathrm{d}, *}$

* Corresponding author. E-mail address: hhuman@zoology.up.ac.za.

${ }^{a}$ Department of Agricultural Sciences; Alma Mater Studiorum University of Bologna, viale Giuseppe Fanin 42, 40127, Bologna, Italy.

${ }^{\mathrm{b}}$ Honey Bee and Silkworm Research Unit; Council for Agricultural Research and Economics (CREA-API), via di Saliceto 80, 40128, Bologna, Italy.

${ }^{c}$ Division of Biological Sciences, Section of Ecology, Behavior, and Evolution; University of California, San Diego,

9500 Gilman Drive, MC0116, La Jolla, CA 92093-0116

${ }^{\mathrm{d}}$ Department of Zoology and Entomology; University of Pretoria,

Private Bag X20, Hatfield 0028, Pretoria, South Africa.

${ }^{1}$ These authors share first authorship

\section{Graphical abstract}
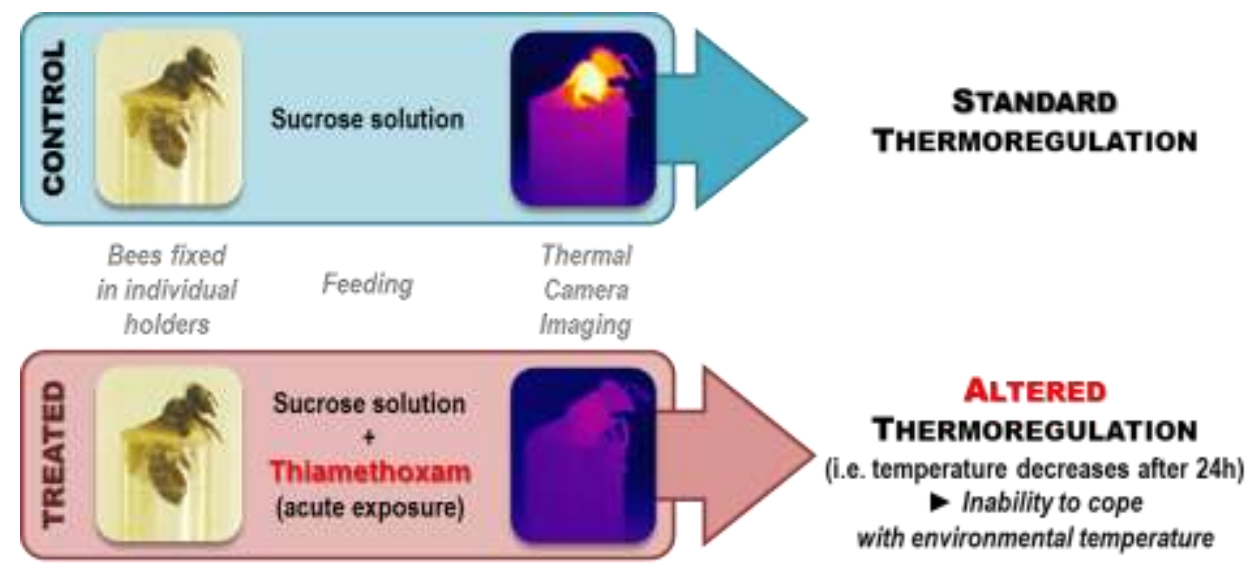


\title{
Highlights
}

- The thorax temperatures of harnessed foragers fed thiamethoxam was measured by thermal imaging

- Acute oral exposure to thiamethoxam significantly altered bee thorax temperature

- The effects depended on dose and environmental temperature

- The alteration starts 1 hour post-treatment and is still present 1 day later

- This thermoregulation alteration may affect colony health through foraging activity

\begin{abstract}
Thiamethoxam is a widely used neonicotinoid pesticide that, as agonist of the nicotinic acetylcholine receptors, has been shown to elicit a variety of sublethal effects in honey bees. However, information concerning neonicotinoid effects on honey bee thermoregulation is lacking. Thermoregulation is an essential ability for the honey bee that guarantees the success of foraging and many in-hive tasks, especially brood rearing. We tested the effects of acute exposure to thiamethoxam $(0.2,1,2 \mathrm{ng} / \mathrm{bee})$ on the thorax temperatures of foragers exposed to low $\left(22^{\circ} \mathrm{C}\right)$ and high $\left(33^{\circ} \mathrm{C}\right)$ temperature environments. Thiamethoxam significantly altered honey bee thorax temperature at all doses tested; the effects elicited varied depending on the environmental temperature and pesticide dose to which individuals were exposed. When bees were exposed to the high temperature environment, the high dose of thiamethoxam increased their thorax temperature $1-2 \mathrm{~h}$ after exposure. When bees were exposed to the low temperature, the higher doses of the neonicotinoid reduced bee thorax temperatures 60-90 min after treatment. In both experiments, the neonicotinoid decreased the temperature of bees the day following the exposure. After a cold shock $\left(5 \mathrm{~min}\right.$ at $\left.4^{\circ} \mathrm{C}\right)$, the two higher doses elicited a decrease of the thorax temperature, while the lower dose caused an increase, compared to the control. These alterations in thermoregulation caused by thiamethoxam may affect bee foraging activity and a variety of in-hive tasks, likely leading to negative consequences at the colony level. Our results shed light on sublethal effect of pesticides which our bees have to deal with.
\end{abstract}

Keywords: thorax temperature, thermogenesis, hypothermia, nicotinic acetylcholine receptors, thiamethoxam, sublethal effects 


\section{Introduction}

Pesticides are widely used in agriculture and veterinary medicine, however they also affect the health of numerous non-target organisms (Desneux et al., 2007; Schäfer et al., 2012). Beside the numerous factors playing a role in colony losses (Vanbergen et al., 2013), recently attention has focused on the effects of neonicotinoid pesticides on honey bees and their possible role in declining health of honey bee colonies (for reviews see Godfray et al., 2014 and Pisa et al., 2014). These systemic insecticides are potent agonists of the nicotinic acetylcholine receptors (nAChR), largely distributed in the insect central nervous system, and can disrupt processes involving cholinergic neurotransmission, such as olfaction, learning and memory (Jones et al., 2006, Armengaud et al., 2002; Williamson and Wright, 2013). Currently, $30 \%$ of the insecticides used worldwide are neonicotinoids (Simon-Delso et al., 2014) and honey bees are exposed to them both in the field (see Krupke and Long, 2015 for review) and inside the hive (Chauzat et al., 2006; Lambert et al., 2013; Mullin et al., 2010; Smodis Skerl et al., 2009). The sublethal effects of neonicotinoids on honey bees have been extensively studied at many different physiological levels, but thermoregulation has been surprisingly overlooked.

Thermoregulation is essential for honey bees both at individual and colony levels and is achieved by both physiological and behavioural processes (Heinrich, 1980a; Heinrich, 1980b; Stabentheiner et al., 1995). Honey bees need to maintain the optimal temperature of the brood during the whole active season $\left(\sim 35^{\circ} \mathrm{C}\right.$, Himmer, 1932; Human et al., 2006) and the winter cluster during the cold periods (Heinrich and Esch, 1994; Jones et al., 2004; Stabentheiner, 2003). Forager bees under colder environmental conditions maintain their thorax above ambient temperature during the foraging cycle using the flight muscles (Coelho, 1991), while under warmer conditions foragers use evaporative cooling to maintain their thorax temperature (Heinrich, 1980a; Nicolson \& Human, 2008). In fact, honey bee flight ability and consequent foraging behaviour depend on thorax temperature (Esch, 1988; Schmaranzer, 2000; Schmaranzer and Stabentheiner, 1988; Stabentheiner, 2001). Foragers control thorax temperature not only during foraging activity outside the hive but also when performing the recruitment dance and unloading food inside the colony (Stabentheiner et al., 1995; Stabentheiner and Hagmuller, 1991). The priority during unloading of foragers is related to their thorax temperature; in general, the hotter the thorax of the forager the more valuable and profitable the receiver perceives the food source to be, so that the forager has to 
wait less than a forager with low thorax temperature to be unloaded (Stabentheiner and Hagmuller, 1991). Therefore, any interference with thermoregulation has implications at both individual and colony levels.

African honey bees have a higher metabolic rate than European honey bees, but their smaller size facilitates heat loss and their thorax temperatures are similar (Heinrich, 1979; Heinrich, 1980a). Because African honey bees have a significantly greater (15\%) engine (thorax) to bee mass ratio (Hepburn et al., 1999), they provide a more sensitive model to test the effects of temperature on thorax muscle activity. Honey bee thermoregulation is impaired by insecticides like organophosphates and pyrethroids that act upon the cholinergic and adrenergic pathways (Belzunces et al., 1996; Schmaranzer et al., 1987; Vandame and Belzunces, 1998), but the effect of neonicotinoids on honey bee body temperature and thermoregulation abilities has not yet been investigated.

In this study, we tested the effects of three acute doses of the neonicotinoid thiamethoxam, a commonly used second-generation neonicotinoid that succeeded the firstgeneration imidacloprid (Maienfisch et al., 2001; Simon-Delso et al., 2014), on the thorax temperature of individual honey bees (Apis mellifera scutellata). Forager bees, compared to in-hive bees, are more frequently exposed to neonicotinoids (i.e. via spray and food contamination) and exposed to a wider variety of environmental temperatures (Hepburn and Radloff, 1998; Kovac et al., 2010). Therefore, we tested the effects of thiamethoxam on foragers exposed to either low $\left(22^{\circ} \mathrm{C}\right.$, Experiment 1) or high $\left(33^{\circ} \mathrm{C}\right.$, Experiment 2) temperatures to mimic outside/inside hive temperatures. During neonicotinoid seed-dressed maize sowing (i.e. early spring), early flying foragers can be exposed to both low temperatures and neonicotinoids used for seed treatments, such as thiamethoxam (Nuyttens et al., 2013; Tremolada et al., 2010). Hence, we also investigated the effects of the neonicotinoid on the ability of foragers to recover from critically low temperatures (cold shock). We predicted that the pesticide, by activating the nAChR, may act upon cholinergic pathways and alter thermoregulation. Since flight behaviour and thermoregulation are closely related (Esch, 1976; Schmaranzer, 2000), changes in forager body temperatures could be one of the reasons behind the various sublethal effects elicited by thiamethoxam and other neonicotinoids involving homing and foraging behaviour of bees (Bortolotti et al., 2003; Henry et al., 2012; Henry et al., 2015). 


\section{Materials and methods}

\subsection{Honey bee preparation}

Returning Apis mellifera scutellata nectar foragers were collected from four colonies at the experimental farm of the University of Pretoria, South Africa, in September 2014. After collection, bees were immediately brought to the laboratory. Each individual bee was chilled using ice, then inserted into a Plexiglas tube $(6 \mathrm{~mm}$ diameter $)$ and held in place with a beeswax-colophony mixture applied on the dorsal surface between the thorax and the abdomen. The thorax remained free of any material, since its temperature was the principal endpoint assessed in this study (Fig. 1).
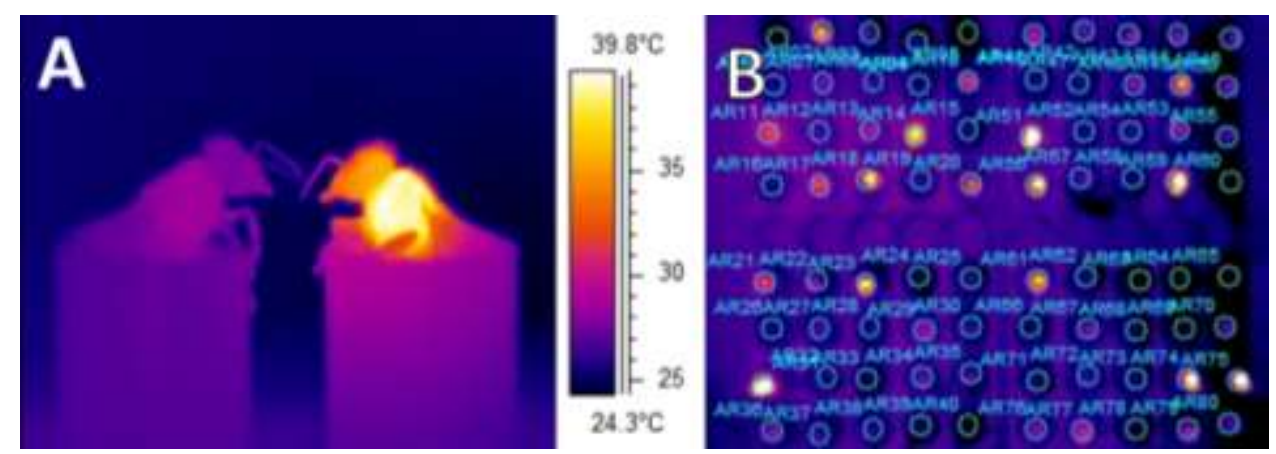

Fig. 1. Thermal photo of harnessed forager bees. (A) A close-up of two foragers inserted and fixed into the Plexiglas tubes; (B) 80 honey bees recorded from above during the experiment: the thorax of each bee was identified and defined by a specific identification code, thus the temperature of each individual was assessed.

Tubes with honey bees were placed upright in a holding rack at a distance that did not allow trophallaxis between individuals. Honey bees were individually fed $3 \mu 1$ of $25 \%$ (w/w) sucrose solution and then placed in an incubator at $33^{\circ} \mathrm{C}$ (Memmert $\mathrm{HCP} 108, \mathrm{GmbH}+\mathrm{Co}$. $\mathrm{KG}$, Schwabach, Germany) for one hour to help them recover from the stress of manipulation. The administration of this low sucrose concentration followed by the 1-hour incubation with no food ensured the immediate and full consumption of the test solution provided later.

\subsection{Administration of the test solutions}

After the 1-hour incubation period, bees were placed at room temperature $\left(22^{\circ} \mathrm{C}\right)$ and individually fed $10 \mu \mathrm{l}$ of $50 \%$ (w/w) sucrose solution, according to the guidelines for pesticide toxicity testing on honey bees (OEPP/EPPO, 2010). The test solutions contained pure sucrose (control) or thiamethoxam (Dr. Ehrenstorfer GmbH, 98.0\% purity, CAS\# 153719-23-4) at 0.2 $\mathrm{ng} / \mathrm{bee}$ (low), $1 \mathrm{ng} / \mathrm{bee}$ (medium) or $2 \mathrm{ng} / \mathrm{bee}$ (high dose treatments), corresponding to $20 \mathrm{ppb}$, 
$100 \mathrm{ppb}$ and $200 \mathrm{ppb}$ respectively (acetone was used as solvent, $<0.02 \%$ in all treatments and controls). The doses consumed by the bees were respectively 25,5 and 2.5 times lower than the $\mathrm{LD}_{50}$ of thiamethoxam for honey bees, which is considered to be $5 \mathrm{ng} / \mathrm{bee}$ (EFSA, 2013). Each bee received a randomly assigned treatment and those that did not consume the test solution completely were excluded from the experiment.

\subsection{Temperature assessment}

The thorax temperature of the harnessed honey bees was recorded using a FLIR SC325 thermal camera (FLIR USA). The camera was positioned vertically above the bees for simultaneous recording of the temperature of 80 individuals ( 4 treatments and 20 bees per treatment). The thorax temperature of each bee was targeted and defined by a unique identification code throughout the whole experiment (Fig. 1). The first temperature recording was done before treatment (Day 1 at time 0, between 12:00 h and 13:00 h) followed by

subsequent recording, all carried out in a laboratory maintained at $22^{\circ} \mathrm{C}$. The Day 2 measurements started between 08:00 $\mathrm{h}$ and 10:00 h. Two experiments were conducted to test the effect of acute oral exposures of thiamethoxam on honey bee thermoregulation.

2.3.1. Experiment 1: Low constant temperature and cold shock

After administration of the test solution, the bees were maintained at $22^{\circ} \mathrm{C}$. On this day (Day 1) their thorax temperature was recorded every $30 \mathrm{~min}$ for a total of $4 \mathrm{~h}$ (from time 0 to time 240). Additional recordings were made 1 and $2 \mathrm{~h}$ after treatment: 70, 80, 130 and 140 min post-treatment. When the recording on Day 1 was completed, the bees were fed $50 \%$ (w/w) sucrose ad libitum and maintained in the incubator at $33^{\circ} \mathrm{C}$ to guarantee their survival overnight. On the second day (Day 2), bees were removed from the incubator and fed with $50 \%$ sucrose solution. This procedure is routinely used in long-term memory experiments on harnessed bees to avoid starvation (Wustenberg et al. 1998; El Hassani et al. 2012). Their thorax temperature was recorded for a total of $1 \mathrm{~h}$ : every $10 \mathrm{~min}$ for $30 \mathrm{~min}$ and then at 60 min (time 1200, 1210, 1220, 1230, 1260). Thorax temperatures of a total of 302 bees were recorded during four experimental replicates.

After the 1-hour recording on Day 2, a cold shock (CS) was performed by keeping honey bees at $4^{\circ} \mathrm{C}$ for $5 \mathrm{~min}$. Their thorax temperature was thereafter assessed every $10 \mathrm{~min}$ for 30 min total (time 0, 10, 20 and 30). This part of the experiment was repeated twice for a total of 140 bees. 


\subsubsection{Experiment 2: High temperature}

After administration of the test solutions, the bees were incubated at $33^{\circ} \mathrm{C}$. Exactly $1 \mathrm{~h}$ and $2 \mathrm{~h}$ after treatment, bees were moved from the incubator to a colder environment at $22^{\circ} \mathrm{C}$ for $20 \mathrm{~min}$. During these $20 \mathrm{~min}$, their thorax temperature was recorded every $10 \mathrm{~min}$ (Day 1 , time 60, 70, 80, 120, 130 and 140, similar to Exp. 1). The following day (Day 2), their thorax temperature was recorded at time 1200, 1210 and 1220. This experiment was repeated four times for a total of 308 tested individuals.

\subsection{Statistical analysis}

The Kruskal-Wallis Rank-Sum test was used to test the effects of thiamethoxam dose $(0,0.2,1,2 \mathrm{ng} / \mathrm{bee})$ on forager bee thorax temperatures overall and at each time assessment. Significant effects were further analysed using Wilcoxon paired comparisons among different dose levels. Sequential Bonferroni correction was applied (Sokal and Rohlf, 1995) to correct for 6 pairwise comparisons leading to an adjusted $\alpha=0.0083$. The non-parametric test was used since the temperature data from both experiments were not normally distributed (Shapiro Normality tests, $\mathrm{p}<0.0001$ for all time assessments, Pirk et al., 2013). All foragers without a full first day of records were excluded from the temperature analysis. Kaplan-Maier survival analyses were used to test the effects of thiamethoxam dose $(0,0.2,1,2 \mathrm{ng} / \mathrm{bee})$ on honey bee mortality after one day. Log-Rank Mantel-Cox values are reported. All analyses were computed using JMP v10.0, SAS statistical software and SPSS22 software (SPSS Science, IBM, Armonk, NY, USA). All measurements are reported as mean \pm SE throughout the text.

\section{Results}

\subsection{Experiment 1: Low constant temperature and cold shock}

The results of this experiment are summarized in Table 1 and Fig. 2. The statistical parameters of the Wilcoxon paired comparisons for each time interval are reported in Table S1.

On Day 1, there was an overall significant effect of treatment on the thorax temperature of the bees (Kruskal-Wallis Rank-Sum test, $\chi^{2}(3)=18.70, p=0.0003$ ). Wilcoxon paired comparison ( $\mathrm{p}<0.0083$ after sequential Bonferroni correction) showed that the thorax temperatures of medium-dose treated bees (medium) $\left(25.95 \pm 0.09^{\circ} \mathrm{C}\right)$ and high-dose treated bees (high) $\left(26.06 \pm 0.11{ }^{\circ} \mathrm{C}\right)$ were significantly lower than low-dose treated bees (low) $\left(26.37 \pm 0.09^{\circ} \mathrm{C}\right)$, while there was no significant difference between control bees (control) 
$\left(26.22 \pm 0.10^{\circ} \mathrm{C}\right)$ and any other treatment. There was a significant effect of treatment on forager thorax temperatures at 60, 70, 80 and 90 min post-treatment during Day 1 (Table 1). Subsequent Wilcoxon paired comparison showed that high had a significantly lower temperature than low at $60\left(\Delta \mathrm{T}=-1.46^{\circ} \mathrm{C}\right), 70\left(-1.04^{\circ} \mathrm{C}\right)$ and $80\left(-1.12^{\circ} \mathrm{C}\right)$ min post-treatment and medium 60 min post-treatment $\left(-0.53{ }^{\circ} \mathrm{C}\right)$. There was no statistically significant difference between any other doses within these periods. One hour after treatment, high showed an increase of temperature and from $140 \mathrm{~min}$ to the end of Day 1 had the highest temperature among all treatments.

On Day 2 there was an overall significant effect of treatment on the thorax temperature (Kruskal-Wallis Rank-Sum test, $\chi^{2}(3)=59.15$, p $<0.0001$ ). Wilcoxon paired comparison showed that the overall thorax temperature of the high treatment $\left(25.90 \pm 0.18^{\circ} \mathrm{C}\right)$ was significantly lower than control $\left(27.95 \pm 0.22^{\circ} \mathrm{C}\right)$, low $\left(28.17 \pm 0.24^{\circ} \mathrm{C}\right)$ and medium treatments $\left(27.87 \pm 0.26^{\circ} \mathrm{C}\right)$. This significant effect was consistent across all recording times during Day 2 (Table 1).

There was a significant effect of the neonicotinoid treatment on the thorax temperature of the honey bees after the cold shock (CS) (Kruskal-Wallis Rank-Sum test, $\chi^{2}(3)=33.50, \mathrm{p}$ $<0.0001)$. Subsequent Wilcoxon paired comparison showed that medium $\left(24.43 \pm 0.15^{\circ} \mathrm{C}\right)$ and $h i g h\left(24.42 \pm 0.21^{\circ} \mathrm{C}\right)$ thorax temperatures were significantly lower than control $(25.54 \pm$ $\left.0.27^{\circ} \mathrm{C}\right)$ ) and $\operatorname{low}\left(25.76 \pm 0.29^{\circ} \mathrm{C}\right)$. There was a significant effect of treatment at 20 and 30 min after the CS (Table 1 and Fig. 2, time 1290 and 1300). Specifically, 20 min post-CS medium and high had a significantly lower temperature than control (respectively -0.75 and $0.71^{\circ} \mathrm{C}$ ) and low (respectively -1.61 and $-1.57^{\circ} \mathrm{C}$ ). Also, 30 min after the CS, low thorax temperature was significantly higher than control $\left(+1.84^{\circ} \mathrm{C}\right)$, medium $\left(+2.24^{\circ} \mathrm{C}\right)$ and high $\left(+2.16^{\circ} \mathrm{C}\right)$; in addition, medium and high had a significantly lower thorax temperature than control (respectively -0.60 and $-0.32^{\circ} \mathrm{C}$ ). 


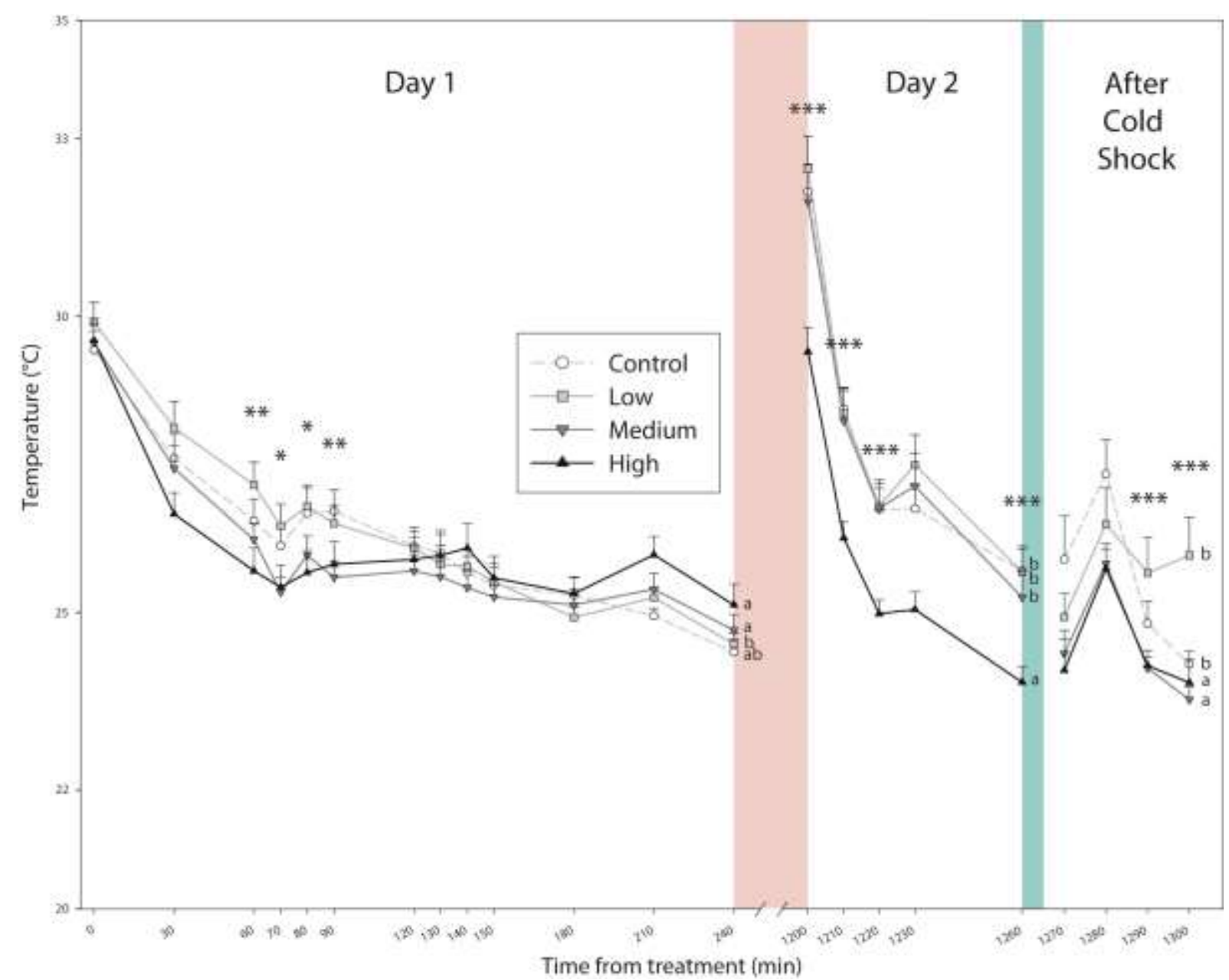

Fig. 2. Experiment 1: mean thorax temperatures $( \pm \mathrm{SE})$ of harnessed forager honey bees maintained at $22^{\circ} \mathrm{C}$ after acute exposure to thiamethoxam. Bees were incubated at $33^{\circ} \mathrm{C}$ overnight (red background) and maintained at $22^{\circ} \mathrm{C}$ when the temperature recordings were done. On Day 2, a cold shock was performed (5 min at $4^{\circ} \mathrm{C}$, dark blue background). The overall effect of dose $(0,0.2,1,2 \mathrm{ng} / \mathrm{bee}$, respectively control and low, medium and high dose of thiamethoxam) was statistically significant in each time period (Kruskal-Wallis RankSum test at Day 1, Day 2 and After CS, respectively $p=0.0008, p<0.0001, p<0.0001)$. Asterisks indicate significant differences between doses at specific recording times (Kruskal-Wallis Rank-Sum test, $* \mathrm{p}<0.05, * *$ $\mathrm{p}<0.01, * * * \mathrm{p}<0.001)$. Different letters indicate statistical differences between doses in each time period (Wilcoxon paired test, $\mathrm{p}<0.0083$ after Bonferroni correction). Further post hoc comparisons are reported in Table 1 and S1. 
Table 1. Summary of the results of Experiment 1. Kruskal-Wallis test (DF = 3) was used to assess significant effects (bold) of treatment at each recording time. The mean (SE) thorax temperature of the honey bees in relation to time and tested dose (control and low, medium and high doses of thiamethoxam, respectively $0,0.2$, 1, 2 ng/bee) are reported. Different letters, consistent with Fig.2, indicate statistically significant differences between doses within time assessments (Wilcoxon paired test, $\mathrm{p}<0.0083$ after Bonferroni correction).

\begin{tabular}{|c|c|c|c|c|c|c|c|c|}
\hline \multirow{2}{*}{ Period } & \multirow{2}{*}{$\begin{array}{l}\text { Time } \\
\text { (min) }\end{array}$} & \multirow{2}{*}{$\mathbf{N}$} & \multirow{2}{*}{$x^{2}$} & \multirow{2}{*}{$P$ value } & \multicolumn{4}{|c|}{ Mean thorax temperature $(\mathrm{SE})\left({ }^{\circ} \mathrm{C}\right)$} \\
\hline & & & & & Control & Low & Medium & High \\
\hline \multirow{13}{*}{ Day 1} & 0 & 302 & 2.15 & 0.5423 & $29.43(0.32)$ & $29.90(0.33)$ & $29.56(0.32)$ & 29.59 (0.37) \\
\hline & 30 & 302 & 6.48 & 0.0905 & $27.61(0.41)$ & $28.12(0.44)$ & $27.43(0.38)$ & $26.66(0.36)$ \\
\hline & 60 & 302 & 14.08 & 0.0028 & $26.55(0.37) a b$ & $27.16(0.38) b$ & $26.23(0.27) b$ & $25.70(0.39) \mathrm{a}$ \\
\hline & 70 & 302 & 9.24 & 0.0262 & $26.12(0.34) \mathrm{ab}$ & $26.46(0.37) b$ & $25.34(0.25) \mathrm{ab}$ & $25.42(0.37) \mathrm{a}$ \\
\hline & 80 & 302 & 9.86 & 0.0198 & $26.68(0.42) a b$ & $26.79(0.37) b$ & $25.96(0.32) a b$ & $25.67(0.38) \mathrm{a}$ \\
\hline & 90 & 302 & 11.40 & 0.0098 & $26.71(0.36) \mathrm{a}$ & $26.50(0.31) a$ & $25.59(0.27) \mathrm{a}$ & $25.81(0.38) a$ \\
\hline & 120 & 302 & 2.95 & 0.7437 & $26.12(0.31)$ & $26.08(0.29)$ & $25.70(0.28)$ & $25.89(0.38)$ \\
\hline & 130 & 302 & 1.17 & 0.7597 & $26.00(0.32)$ & $25.81(0.32)$ & $25.61(0.29)$ & $25.97(0.42)$ \\
\hline & 140 & 302 & 2.41 & 0.4923 & $25.67(0.28)$ & $25.79(0.27)$ & $25.42(0.28)$ & $26.09(0.42)$ \\
\hline & 150 & 302 & 1.24 & 0.7437 & $25.47(0.3)$ & $25.52(0.31)$ & $25.26(0.29)$ & $25.59(0.36)$ \\
\hline & 180 & 301 & 3.20 & 0.3615 & $25.29(0.31)$ & $24.92(0.16)$ & $25.13(0.27)$ & $25.32(0.27)$ \\
\hline & 210 & 301 & 7.56 & 0.0561 & $24.94(0.13)$ & $25.25(0.16)$ & $25.39(0.28)$ & $25.97(0.31)$ \\
\hline & 240 & 299 & 4.39 & 0.222 & $24.33(0.22)$ & $24.47(0.18)$ & $24.70(0.27)$ & $25.13(0.35)$ \\
\hline \multirow{5}{*}{ Day 2} & 1200 & 251 & 20.50 & 0.0001 & $32.10(0.47) b$ & $32.49(0.55) b$ & $31.94(0.5) b$ & $29.40(0.41) \mathrm{a}$ \\
\hline & 1210 & 251 & 20.62 & 0.0001 & $28.43(0.37) b$ & $28.36(0.42) b$ & $28.24(0.51) b$ & $26.26(0.27) \mathrm{a}$ \\
\hline & 1220 & 251 & 23.54 & $<0.0001$ & $26.74(0.35) b$ & $26.80(0.39) b$ & $26.76(0.48) b$ & $24.98(0.23) \mathrm{a}$ \\
\hline & 1230 & 251 & 15.75 & 0.0013 & $26.75(0.38) b$ & $27.49(0.51) b$ & $27.14(0.56) b$ & $25.05(0.3) \mathrm{a}$ \\
\hline & 1260 & 250 & 22.10 & $<0.0001$ & $25.70(0.43) b$ & $25.68(0.39) b$ & $25.25(0.45) b$ & $23.82(0.27) \mathrm{a}$ \\
\hline \multirow{4}{*}{$\begin{array}{c}\text { After } \\
\text { Cold } \\
\text { Shock }\end{array}$} & 1270 & 140 & 7.69 & 0.0528 & $25.90(0.73)$ & $24.92(0.4)$ & $24.30(0.39)$ & $24.02(0.53)$ \\
\hline & 1280 & 140 & 7.05 & 0.0703 & $27.33(0.58)$ & $26.49(0.61)$ & $25.83(0.23)$ & $25.74(0.42)$ \\
\hline & 1290 & 140 & 21.69 & $<0.0001$ & $24.81(0.37) b$ & $25.67(0.6) b$ & $24.06(0.19) a$ & $24.10(0.26) \mathrm{a}$ \\
\hline & 1300 & 140 & 33.04 & $<0.0001$ & $24.13(0.22) \mathrm{c}$ & $25.97(0.64) b$ & $23.53(0.21) a$ & $23.81(0.39) \mathrm{a}$ \\
\hline
\end{tabular}




\subsection{Experiment 2: High temperature}

The results of this experiment are summarized in Table 2 and Fig. 3. The statistical parameters of the Wilcoxon paired comparisons for each time interval are reported in Table S2.

On Day 1, there was a significant effect of treatment on the thorax temperatures of the honey bees (Fig. 3, Kruskal-Wallis Rank-Sum test, $\chi^{2}(3)=57.64, p<0.0001$ ). Wilcoxon paired comparison showed that the thorax temperature of high $\left(30.17 \pm 0.18^{\circ} \mathrm{C}\right)$ was significantly greater than control $\left(29.12 \pm 0.15^{\circ} \mathrm{C}\right)$, low $\left(28.53 \pm 0.13^{\circ} \mathrm{C}\right)$ and medium $\left(28.54 \pm 0.14^{\circ} \mathrm{C}\right)$; in addition, low and medium had a significantly lower thorax temperature than control, while there was no statistical difference between them.

Furthermore, there was a significant effect of neonicotinoid dosage at 80,120, 130 and 140 min post-treatment (Table 2 and Fig. 3). Subsequent Wilcoxon paired comparison showed that at 120 min the bees treated with a high dose had a significantly higher thorax temperature compared to low $\left(\Delta \mathrm{T}=+2.86^{\circ} \mathrm{C}\right)$ and medium $\left(+2.49^{\circ} \mathrm{C}\right)$ and that the thorax temperature of low was significantly lower than control $\left(-1.39^{\circ} \mathrm{C}\right)$. At both 130 and $140 \mathrm{~min}$ post-treatment, high had a significantly higher temperature than control $\left(+2.17\right.$ and $+1.74{ }^{\circ} \mathrm{C}$, respectively), low $\left(+2.91\right.$ and $+2.46^{\circ} \mathrm{C}$, respectively) and medium $\left(+2.88\right.$ and $+2.20^{\circ} \mathrm{C}$, respectively). On Day 2, there was no significant effect of thiamethoxam dose on the thorax temperatures of the bees (Kruskal-Wallis Rank-Sum test, $\chi^{2}(3)=4.80, p<0.1868$ ). 


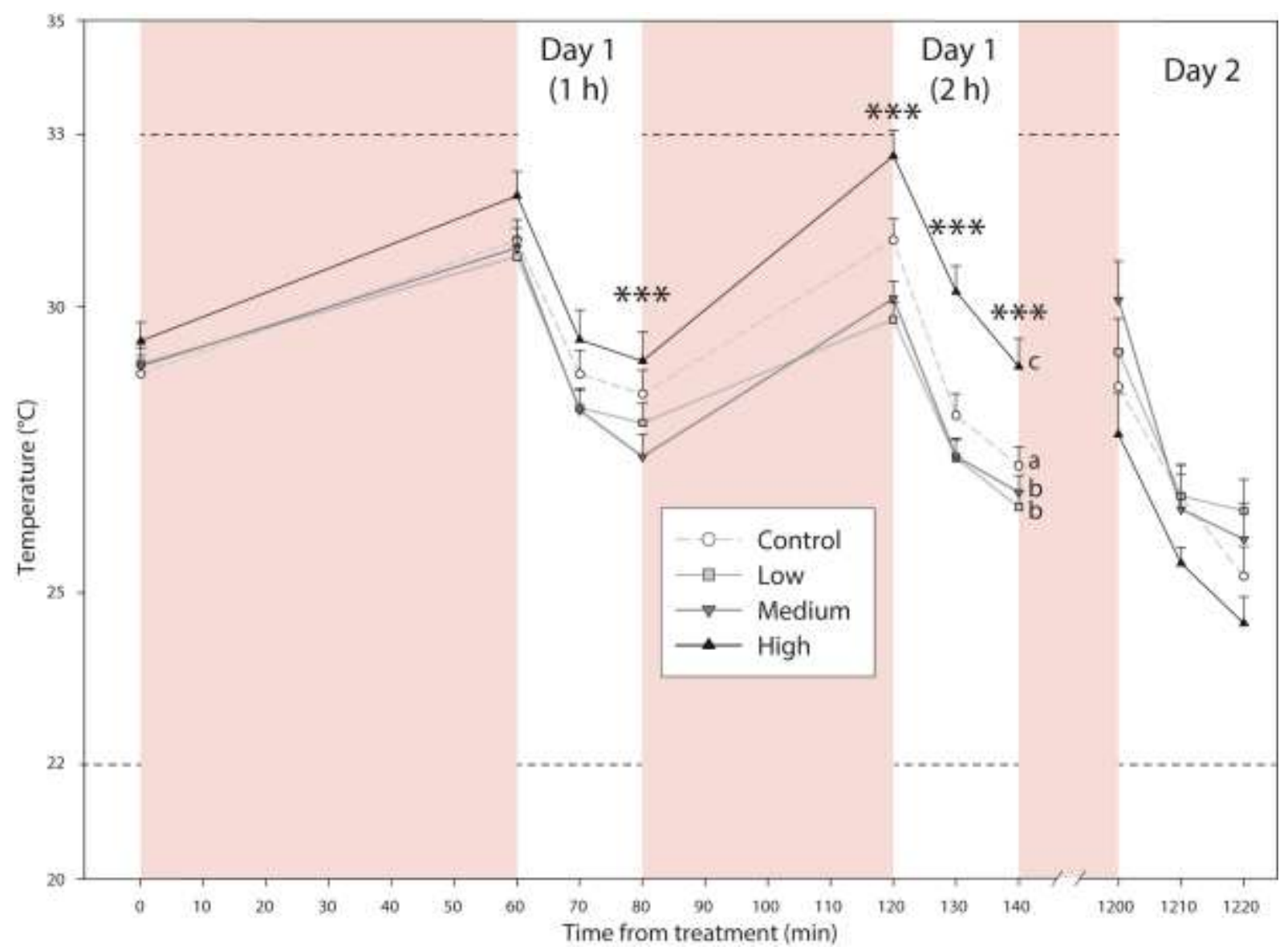

Fig. 3. Experiment 2: mean thorax temperatures $( \pm \mathrm{SE})$ of harnessed forager honey bees maintained at $3^{\circ} \mathrm{C}$ after acute exposure to thiamethoxam. The dashed lines show the temperature to which bees were exposed across time: $33^{\circ} \mathrm{C}$ (red background) and $22^{\circ} \mathrm{C}$ (when the temperature recordings were done, white background). The effect of treatment $(0,0.2,1,2 \mathrm{ng} / \mathrm{bee}$, respectively control and low, medium and high dose of thiamethoxam) was statistically significant during Day 1 (Kruskal-Wallis Rank-Sum test, p<0.0001). Asterisks indicate statistically significant differences between doses within specific time recordings (Kruskal-Wallis RankSum test, $* \mathrm{p}<0.05, * * \mathrm{p}<0.01, * * * \mathrm{p}<0.001)$. Different letters indicate statistically significant differences between doses (Wilcoxon paired test, $\mathrm{p}<0.0083$ after Bonferroni correction). Further post hoc comparisons are reported in Table 2 and $\mathrm{S} 2$. 
Table 2. Summary of the results of Experiment 2. The Kruskal-Wallis test ( $D F=3$ ) was used to assess significant effects (bold) of treatment at each time assessment. The mean (SE) thorax temperature of the honey bees in relation to time and dose (control and low, medium and high doses of thiamethoxam, respectively $0,0.2$, 1, 2 ng/bee) are reported. Different letters, consistent with Fig.3, indicate statistically significant differences between doses (Wilcoxon paired test, $\mathrm{p}<0.0083$ after Bonferroni correction).

\begin{tabular}{|c|c|c|c|c|c|c|c|c|}
\hline \multirow{2}{*}{ Period } & \multirow{2}{*}{$\begin{array}{l}\text { Time } \\
\text { (min) }\end{array}$} & \multirow{2}{*}{$\mathbf{N}$} & \multirow{2}{*}{2} & \multirow{2}{*}{$P$ value } & \multicolumn{4}{|c|}{ Mean thorax temperature $(\mathrm{SE})\left({ }^{\circ} \mathrm{C}\right)$} \\
\hline & & & & & Control & Low & Medium & High \\
\hline Before & 0 & 308 & 3.25 & 0.3547 & $28.83(0.32)$ & $29.00(0.35)$ & $28.99(0.32)$ & $29.39(0.34)$ \\
\hline \multirow{3}{*}{$\begin{array}{c}\text { Day } 1 \\
1 \mathrm{~h}\end{array}$} & 60 & 308 & 2.56 & 0.4641 & $31.19(0.36)$ & $30.87(0.32)$ & $30.92(0.33)$ & $31.86(0.43)$ \\
\hline & 70 & 308 & 1.92 & 0.5894 & $28.84(0.42)$ & $28.22(0.31)$ & $28.21(0.39)$ & $29.25(0.51)$ \\
\hline & 80 & 308 & 8.92 & 0.0303 & $28.49(0.42) \mathrm{a}$ & $27.97(0.34) \mathrm{a}$ & $27.4(0.39) \mathrm{a}$ & $28.86(0.48) \mathrm{a}$ \\
\hline \multirow{3}{*}{$\begin{array}{c}\text { Day } 1 \\
2 \mathrm{~h}\end{array}$} & 120 & 308 & 28.19 & $<0.0001$ & $31.16(0.37) b c$ & $29.77(0.29) \mathrm{a}$ & $30.14(0.3) a b$ & $32.63(0.45) c$ \\
\hline & 130 & 308 & 34.40 & $<0.0001$ & $28.09(0.38)$ a & $27.35(0.32) a$ & $27.38(0.32)$ a & $30.26(0.45) b$ \\
\hline & 140 & 308 & 22.64 & $<0.0001$ & $27.21(0.33) \mathrm{a}$ & $26.49(0.29) \mathrm{a}$ & $26.75(0.29) \mathrm{a}$ & $28.95(0.48) b$ \\
\hline \multirow{3}{*}{ Day 2} & 1200 & 141 & 5.60 & 0.1330 & $28.60(0.63)$ & 29.20 (0.59) & $30.11(0.67)$ & $27.76(0.71)$ \\
\hline & 1210 & 141 & 0.89 & 0.8286 & $26.68(0.56)$ & $26.69(0.54)$ & $26.45(0.6)$ & $25.51(0.28)$ \\
\hline & 1220 & 141 & 5.61 & 0.1323 & $25.29(0.52)$ & $26.43(0.55)$ & $25.93(0.63)$ & $24.46(0.46)$ \\
\hline
\end{tabular}

\subsection{Mortality}

There was a significant effect of treatment on honey bee mortality between Day 1 and Day 2 (Kaplan-Meier survival analysis, Log Rank Mantel-Cox; Exp. 1: $\chi^{2}=18.175$, df $=3$, p $<0.001$; Exp. 2: $\left.\chi^{2}=19.390, d f=3, p<0.001\right)$. In Experiment 1, the mortality of foragers receiving the high treatment ( 7.0 bees \pm 1.5$)$ was significantly higher than control (3.0 bees \pm 1.5; $\left.\chi^{2}=10.139, \mathrm{p}=0.001\right)$ and low $\left(2.8\right.$ bees $\left.\pm 1.1 ; \chi^{2}=10.579, \mathrm{p}=0.001\right)$. In Experiment 2 , the mortality of bees receiving the same high treatment ( 15.5 bees \pm 1.5$)$ was significantly higher than all others (control, 10.3 bees $\pm 2.4 ; \chi^{2}=8.431, p=0.004$; low, 8.0 bees $\pm 2.3 ; \chi^{2}=14.296$, $\mathrm{p}<0.001$; medium, 9.5 bees $\left.\pm 1.5 ; \chi^{2}=14.357, \mathrm{p}<0.001\right)$. In both Exp. 1 and 2, there was no significant effect of low and medium treatments on mortality.

\section{Discussion}

Acute oral exposure to thiamethoxam significantly altered the thorax temperature of $A$. m. scutellata foragers from the first hour to at least $24 \mathrm{~h}$ after exposure. The thorax temperature of forager bees exposed to the higher neonicotinoid doses was closer to the 
environmental temperature in all experiments, suggesting an impairment of their thermoregulation abilities. When foragers were maintained at low temperature $\left(22^{\circ} \mathrm{C}\right)$, the temperature of foragers treated with the higher doses of thiamethoxam decreased rapidly after exposure, and this effect persists for at least $24 \mathrm{~h}$ (Fig. 2 and Table 1). Bees treated with the higher doses of pesticide also showed reduced ability to recover from a 5-min cold shock at $4^{\circ} \mathrm{C}$ (Fig. 2 and Table 1). Foragers that were maintained at high temperature $\left(33^{\circ} \mathrm{C}\right)$ had significantly higher thorax temperatures when treated with the pesticide (high dose) in the shorter term (Day 1, Fig. 3 and Table 2).

Previous studies showed that the neonicotinoid imidacloprid elicits hyperactivity behaviour in honey bees and German cockroaches (Suchail et al., 2001; Wen and Scott, 1997), shortly after treatment. In our experiments, the pesticide might have elicited a muscular excitation of the harnessed honey bees, which led to the increased thorax temperature. The higher temperatures showed by high-dose treated honey bees during the first day of the experiments likely caused a faster energy depletion (Kovac et al., 2010), which can impair proper thermoregulation and may thus explain the lower temperatures of high-dose treated bees observed on Day 2 in both experiments.

The complex interaction between the systemic neonicotinoid insecticides and the nAChR of insects (Belzunces et al., 2012; Decourtye and Devillers, 2010) frequently leads to variability in neonicotinoid effects on honey bees (Guez et al., 2001; Lambin et al., 2001; Suchail et al., 2001). Our results seem to reflect the kinetics of thiamethoxam action upon nAChR (Barbara et al., 2008, Thany 2010): first, a fast saturation activating all the receptors, eliciting thermogenesis; then second, a long desensitized period where the nAChRs cannot be activated again, eventually leading to hypothermia. The effect of pesticides on the cholinergic pathway involved in thermoregulation through inhibition of cholinesterase is already known (Vandame and Belzunces 1998), but our study is the first demonstration of a neonicotinoid causing such impairment in thermoregulation. Together with the effects on thermoregulation, the high dose also decreased the overnight survival of the bees, while the medium and low doses did not elicit any significant effect on survival.

The effect of thiamethoxam on thorax temperature varied in relation to the dose ingested, but the direction of the effect depended on the environmental temperature. Specifically, the dose-response curve was non-monotonic (i.e. not either entirely increasing or decreasing trend) in both experiments. In fact, thiamethoxam caused an increase of the 
foragers' thorax temperature at lower doses and a decrease at higher doses, compared to controls, in the shorter term (Day 1 of Exp. 1, Fig. S1) and longer term (Day 2 of both experiments, Fig. S1 and S2). The same phenomenon, but with an opposite trend, was observed in the shorter term in the high temperature conditions (Day 1 of Exp. 2, Fig. S2): at increasing thiamethoxam dose the bee thorax temperature initially decreased (low and medium doses) to further reach values higher than control (high dose). These opposite trends observed between Exp. 1 and 2 in the short term are related to the environmental temperature to which foragers were exposed (respectively 22 and $33^{\circ} \mathrm{C}$ ), and show the complexity of the physiological effects that thiamethoxam elicits on honey bees. Therefore, the environmental temperature which bees are exposed to, influence the response of bees to the intoxication, possibly playing a role in their detoxification processes.

Sublethal doses of the neonicotinoids thiamethoxam, imidacloprid and acetamiprid impair bee behaviour and motor functions (Aliouane et al., 2009; Charreton et al., 2015 ; Lambin et al., 2001; Williamson et al., 2014). Since honey bees use their muscles to produce heat (Esch, 1976), the impaired thermoregulation could be caused by the effect of the pesticide on thoracic muscle activity. Flight performance depends on muscle activity, and flight muscle temperature is precisely controlled by honey bees during flight (Esch, 1988; Schmaranzer, 2000; Stabentheiner, 2001). Henry et al. (2012, 2015) showed that sublethal doses of thiamethoxam decreased honey bee homing success, thus impairing colony fitness. Furthermore, thoracic temperature is important in trophallactic food exchanges involved in heating the brood nest, with hotter bees which heat the cells receiving food from cooler donors (Basile et al. 2008). Small differences in thorax temperature $\left( \pm 0.5^{\circ} \mathrm{C}\right)$ are used as a cue to identify these two categories of bees, which ensures optimal heating of the brood; any reduction in the temperature will negatively affect the underlying task allocation processes (Basile et al 2008). In our experiments, we observed temperature differences greater than $2.0^{\circ} \mathrm{C}$. Thus, we can conclude from our results that alteration of thermoregulation through neonicotinoid exposure may contribute to decreased homing success of foragers and altered task allocation within the nest, possibly leading to impaired colony fitness.

\section{Conclusion}

Acute oral exposure to thiamethoxam alters the thorax temperature of $A . m$. scutellata foragers from one hour after exposure and for at least one day. This change in 
thermoregulation likely affects colony foraging efficiency through an alteration of both inhive tasks and outside-hive tasks, such as recruitment dance, food unloading, flight performance (Kovac et al., 2010; Stabentheiner et al., 1995; Stabentheiner et al., 2001; Stabentheiner and Hagmull, 1991). The effects of thiamethoxam on individual honey bee thermoregulation may involve a broad range of processes (i.e. flight/homing ability and task allocation) affecting overall colony fitness, and could contribute to colony exhaustion and loss.

\section{Conflict of interests}

The authors declare that they have no competing interests.

\section{Funding}

This work was supported by the University of Pretoria, the National Research Foundation of South Africa, the BBSRC Insect Pollinators initiative (BB/1000968/1) and the Marco Polo scholarship, awarded by University of Bologna to ST. The funding sources had no involvement in the study design, collection, analysis and interpretation of the data, writing and decision to submit the article for publication.

\section{Acknowledgments}

We would like to thank Kendall Crous for beekeeping and invaluable help in the laboratory throughout the experiments.

\section{References}

Aliouane, Y., El Hassani, A. K., Gary, V., Armengaud, C., Lambin, M., Gauthier, M. (2009). Subchronic exposure of honeybees to sublethal doses of pesticides: effects on behavior. Environmental Toxicology and Chemistry 28, 113-22.

Armengaud, C., Lambin, M. and Gauthier, M. (2002). Effects of imidacloprid on the neural processes of memory in honey bees. In Devillers, J; Pham-Delegue, M.H., Honey bees: estimating the environmental impact of chemicals, Taylor \& Francis New York, pp. 85-100. 
Barbara, G., Grünewald, B., Paute, S., Gauthier, M., and Raymond-Delpech, V. (2008). Study of nicotinic acetylcholine receptors on cultured antennal lobe neurones from adult honeybee brains. Invertebrate Neuroscience 8, 19-29.

Basile, R., Pirk, C.W.W. and Tautz, J. (2008). Trophallactic activities in the honeybee brood nest - Heaters get supplied with high performance fuel. Zoology 111, 433-441.

Belzunces, L. P., Vandame, R. and Gu, X. (1996). Modulation of honey bee thermoregulation by adrenergic compounds. Neuroreport 7, 1601-1604.

Belzunces, L. P., Tchamitchian, S. and Brunet, J.-L. (2012). Neural effects of insecticides in the honey bee. Apidologie 43, 348-370.

Bortolotti, L., Montanari, R., Marcelino, J., Medrzycki, P., Maini, S. and Porrini, C. (2003). Effects of sub-lethal imidacloprid doses on the homing rate and foraging activity of honey bees. Bulletin of Insectology 56, 63-67.

Charreton, M., Decourtye, A., Henry, M., Rodet, G., Sandoz, J.-C., Charnet, P. and Collet, C. (2015). A locomotor deficit induced by sublethal doses of pyrethroid and neonicotinoid insecticides in the honeybee Apis mellifera. PLoS ONE 10, e0144879.

Chauzat, M., Faucon, J., Martel, A., Lachaize, J., Cougoule, N. and Aubert, M. (2006). A survey of pesticide residues in pollen loads collected by honey bees in France. Journal of Economic Entomology 99, 253-262.

Coelho, J. R. (1991). Heat transfer and body temperature in honey bee (Hymenoptera: Apidae) drones and workers. Environmental Entomology 20, 1627-1635.

Decourtye, A. and Devillers, J. (2010). Ecotoxicity of neonicotinoid insecticides to bees. In: Thany, S. (Ed.), Insect Nicotinic Acetylcholine Receptors, Advances in Experimental Medicine and Biology 683. Springer New York, pp.85-95.

Desneux, N., Decourtye, A. and Delpuech, J.-M. M. (2007). The sublethal effects of pesticides on beneficial arthropods. Annual Review of Entomology 52, 81-106.

EFSA (2013). Conclusion on the peer review of the pesticide risk assessment for bees for the active substance thiamethoxam. EFSA Journal. 11, 3067.

OEPP/EPPO (2010). Efficacy evaluation of plant protection products. Side-effects on honeybees. OEPP/EPPO Bulletin PP 1/170. 40, 313-319.

EI Hassani, A.K., Schuster, S., Dyck, Y., Demares, F., Leboulle, G. and Armengaud, C. (2012). Identification, localization and function of glutamate-gated chloride channel 
receptors in the honeybee brain. European Journal of Neuroscience 36(4), 2409-20. doi: 10.1111/j.1460-9568.2012.08144.x.

Esch, H. (1976). Body temperature and flight performance of honey bees in a servomechanically controlled wind tunnel. Journal of Comparative Physiology A 109, 265277.

Esch, H. (1988). The effects of temperature on flight muscle potentials in honeybees and cuculiinid winter moths. Journal of Experimental Biology 135, 109-117.

Godfray, H. C. J., Blacquière, T., Field, L. M., Hails, R. S., Petrokofsky, G., Potts, S. G., Raine, N. E., Vanbergen, A. J., Mclean, A. R. (2014). A restatement of the natural science evidence base concerning neonicotinoid insecticides and insect pollinators. Proceedings of the Royal Society of London B 281, 20140558.

Guez, D., Suchail, S., Gauthier, M., Maleszka, R. and Belzunces, L. P. (2001). Contrasting effects of imidacloprid on habituation in 7- and 8-day-old honeybees (Apis mellifera). Neurobiology of Learning and Memory 76, 183-91.

Heinrich, B. (1979). Thermoregulation of African and European honeybees during foraging, attack, and hive exits and returns. Journal of Experimental Biology 80, 217-229.

Heinrich, B. (1980a). Mechanisms of body-temperature regulation in honeybees, Apis mellifera. I. regulation of head temperature. Journal of Experimental Biology 85, 61-72.

Heinrich, B. (1980b). Mechanisms of body-temperature regulation in honeybees, Apis mellifera. II. Regulation of thoracic temperature at high air temperatures. Journal of Experimental Biology 85, 73-87.

Heinrich, B. and Esch, H. (1994). Thermoregulation in bees. American Scientist 82, 164170.

Henry, M., Béguin, M., Requier, F., Rollin, O., Odoux, J.-F., Aupinel, P., Aptel, J., Tchamitchian, S. and Decourtye, A. (2012). A Common Pesticide Decreases Foraging Success and Survival in Honey Bees. Science 336, 348-50.

Henry, M., Cerrutti, N., Aupinel, P., Decourtye, A., Gayrard, M., Odoux, J.-F., Pissard, A., Rüger, C., Bretagnolle, V. (2015). Reconciling laboratory and field assessments of neonicotinoid toxicity to honeybees. Proceedings of the Royal Society of London B 282. doi:10.1098/rspb.2015.2110

Hepburn, H. R. and Radloff, S. E. (1998). Honeybees of Africa. Berlin: Springer 
Hepburn, H. R., Radloff, S. E. and Fuchs, S. (1999). Flight machinery dimensions of honeybees, Apis mellifera. Journal of Comparative Physiology B 169, 107-112.

Himmer, A. (1932). Temperatureverhältnisse bei den sozialen Hymenopteren. Biological Reviews 7, 224-253.

Human, H., Nicolson, S.W. and Dietemann V. (2006). Do honeybees, Apis mellifera scutellata, regulate humidity in their nest? Naturewissenschaften 93, 397-401.

Jones, J. C., Myerscough, M. R., Graham, S. and Oldroyd, B. P. (2004). Honey bee nest thermoregulation: diversity promotes stability. Science 305, 402-4.

Jones, A. K., Raymond-Delpech, V., Thany, S. H., Gauthier, M. and Sattelle, D. B. (2006). The nicotinic acetylcholine receptor gene family of the honey bee, Apis mellifera. Genome Research 16, 1422-1430.

Kovac, H., Stabentheiner, A. and Schmaranzer, S. (2010). Thermoregulation of water foraging honeybees--balancing of endothermic activity with radiative heat gain and functional requirements. Journal of Insect Physiology 56, 1834-45.

Krupke, C. H. and Long, E. Y. (2015). Intersections between neonicotinoid seed treatments and honey bees. Current Opinion in Insect Science 10, 8-13.

Lambert, O., Piroux, M., Puyo, S., Thorin, C., L’Hostis, M., Wiest, L., Buleté, A., Delbac, F. and Pouliquen, H. (2013). Widespread occurrence of chemical residues in beehive matrices from apiaries located in different landscapes of western France. PLoS ONE 8:e67007, 1-12.

Lambin, M., Armengaud, C., Raymond, S. and Gauthier, M. (2001). Imidaclopridinduced facilitation of the proboscis extension reflex habituation in the honeybee. Archives of Insect Biochemistry and Physiology 48, 129-34.

Maienfisch, P., Huerlimann, H., Rindlisbacher, A., Gsell, L., Dettwiler, H., Haettenschwiler, J., Sieger, E. and Walti, M. (2001). The discovery of thiamethoxam: A second-generation neonicotinoid. Pest Management Science 57, 165-176.

Mullin, C. A., Frazier, M., Frazier, J. L., Ashcraft, S., Simonds, R., Vanengelsdorp, D. and Pettis, J. S. (2010). High levels of miticides and agrochemicals in North American apiaries: implications for honey bee health. PLOS ONE 5, e9754.

Nicolson, S.W., Human, H. (2008). Bees get a head start on honey production. Biology Letters 4, 299-301. doi:10.1098/rsbl.2008.0034 
Nuyttens, D., Devarrewaere, W., Verboven, P. and Foqué, D. (2013). Pesticide-laden dust emission and drift from treated seeds during seed drilling: a review. Pest Management Science 69, 564-75.

OEPP/EPPO (2010). Side-effects on honeybees. EPPO Bulletin 40, 313-319.

Pirk, C. W. W., de Miranda, J. R., Kramer, M., Murray, T. E., Nazzi, F., Shutler, D., van der Steen, J. J. M. and van Dooremalen, C. (2013). Statistical guidelines for Apis mellifera research. Journal of Apicultural Research 52, 1-24.

Pirk, C.W.W., Strauss, U., Yusuf, A., Démares, F. \& Human, H. (2015). Honeybee health in Africa-a review. Apidologie, 1-25.

Pisa, L. W., Amaral-Rogers, V., Belzunces, L. P., Bonmatin, J. M., Downs, C. A., Goulson, D., Kreutzweiser, D. P., Krupke, C., Liess, M., McField, M., Morrissey C.A., Noome D.A., Setelle J., Simon-Delso N., Stark J.D., Van Der Sluijs J.P., Van Dyck H. and Wiemers M. (2014). Effects of neonicotinoids and fipronil on non-target invertebrates. Environmental Science and Pollution Research 22, 68-102.

Schäfer, R. B., von der Ohe, P. C., Rasmussen, J., Kefford, B. J., Beketov, M. A., Schulz, R. and Liess, M. (2012). Thresholds for the effects of pesticides on invertebrate communities and leaf breakdown in stream ecosystems. Environmental Science \& Technology 46, 5134-42.

Schmaranzer, S. (2000). Thermoregulation of water collecting honey bees (Apis mellifera). Journal of Insect Physiology 46, 1187-1194.

Schmaranzer, S. and Stabentheiner, A. (1988). Variability of the thermal behavior of honeybees on a feeding place. Journal of Comparative and Physiological Psychology. B 158, 135-141.

Schmaranzer, S., Stabentheiner, A. and Heran, H. (1987). Effect of Roxion-S (dimethoate) on the body temperature of the honey bee. In: Eder, J., Rembold, H. (eds.) Chemical Biology of Social Insects, p. 241.Verlag, München.

Simon-Delso, N., Amaral-Rogers, V., Belzunces, L.P., Bonmatin, J.M., Chagnon, M., Downs, C., Furlan, L., Gibbons, D.W., Giorio, C., Girolami, V., Goulson, D., Kreutzweiser, D.P., Krupke, C.H., Liess, M., Long, E., McField, M., Mineau, P., Mitchell, E.A.D., Morrissey, C.A., Noome, D.A., Pisa, L., Settele, J., Stark, J.D., Tapparo, A., Van Dyck, H., Van Praagh, J., Van der Sluijs, J.P., Whitehorn, P.R., Wiemers, M. (2015). Systemic insecticides (neonicotinoids and fipronil): trends, uses, 
mode of action and metabolites. Environmental Science and Pollution Research 22, 534.

Smodis Skerl, M. I., Velikonja Bolta, S., Basa Cesnik, H. and Gregorc, A. (2009). Residues of Pesticides in honeybee (Apis mellifera carnica) bee bread and in pollen loads from treated apple orchards. Bulletin of Environmental Contamination and Toxicology 83, 374-7.

Sokal, R. R. and Rohlf, F. J. (1995). Biometry: the principles and practice of statistics in biological research. WH Freeman \& Co: New York.

Stabentheiner, A. (2001). Thermoregulation of dancing bees: Thoracic temperature of pollen and nectar foragers in relation to profitability of foraging and colony need. Journal of Insect Physiology 47, 385-392.

Stabentheiner, A. (2003). Endothermic heat production in honeybee winter clusters. Journal of Experimental Biology 206, 353-358.

Stabentheiner, A., Hagmuller, K. (1991). Sweet food means 'hot dancing' in honey bees. Naturwissenschaften 78, 471-473.

Stabentheiner, A., Kovac, H., Hagmuller, K. (1995). Thermal behavior of round and wagtail dancing honeybees. Journal of Comparative Physiology B 165, 433-444.

Suchail, S., Guez, D. and Belzunces, L. P. (2001). Discrepancy between acute and chronic toxicity induced by imidacloprid and its metabolites in Apis mellifera. Environmental Toxicology and Chemistry 20, 2482-6.

Thany, S. (2010). Neonicotinoid Insecticides, in: Thany, S. (Ed.), Insect Nicotinic Acetylcholine Receptors, Advances in Experimental Medicine and Biology 683. Springer New York, pp. 75-83.

Tremolada, P., Mazzoleni, M., Saliu, F., Colombo, M. and Vighi, M. (2010). Field trial for evaluating the effects on honeybees of corn sown using Cruiser and Celest xl treated seeds. Bulletin of Environmental Contamination and Toxicology 85, 229-34.

Vanbergen, A.J., Baude, M., Biesmeijer, J.C., Britton, N.F., Brown, M.J.F., Brown, M., Bryden, J., Budge, G.E., Bull, J.C., Carvell, C., J., C., Connolly, C.N., Evans, D.J., Feil, E.J., Garratt, M.P., Greco, M.K., Heard, M.S., Jansen, V.A.A., Keeling, M.J., Kunin, W.E., Marris, G.C., Memmott, J., Murray, J.T., Nicolson, S.W., Osborne, J.L., Paxton, R.J., Pirk, C.W.W., Polce, C., Potts, S.G., Priest, N.K., Raine, N.E., Roberts, S., Ryabov, E.V., Shafir, S., Shirley, M.D.F., Simpson, S.J., Stevenson, 
P.C., Stone, G.N., Termansen, M. \& Wright, G.A. (2013). Threats to an ecosystem service: pressures on pollinators. Frontiers in Ecology and the Environment 11, 251-259.

Vandame, R. and Belzunces, L. P (1998). Joint actions of deltamethrin and azole fungicides on honey bee thermoregulation. Neuroscience Letters 251, 57-60.

Wen, Z. and Scott, J. G. (1997). Cross-Resistance to Imidacloprid in Strains of German Cockroach (Blattella germanica) and House Fly (Musca domestica). Pesticide Science 49, 367-371.

Williamson, S. M. and Wright, G. A. (2013). Exposure to multiple cholinergic pesticides impairs olfactory learning and memory in honeybees. Journal of Experimental Biology 216, 1799-1807.

Williamson, S. M., Willis, S. J. and Wright, G. A. (2014). Exposure to neonicotinoids influences the motor function of adult worker honeybees. Ecotoxicology 23, 1409-18.

Wüstenberg, D., Gerber, B. and Menzel, R. (1998). Short communication: long- but not medium-term retention of olfactory memories in honeybees is impaired by actinomycin D and anisomycin. European Journal of Neuroscience 10, 2742-2745. 


\section{SUPPLEMENTARY MATERIAL}

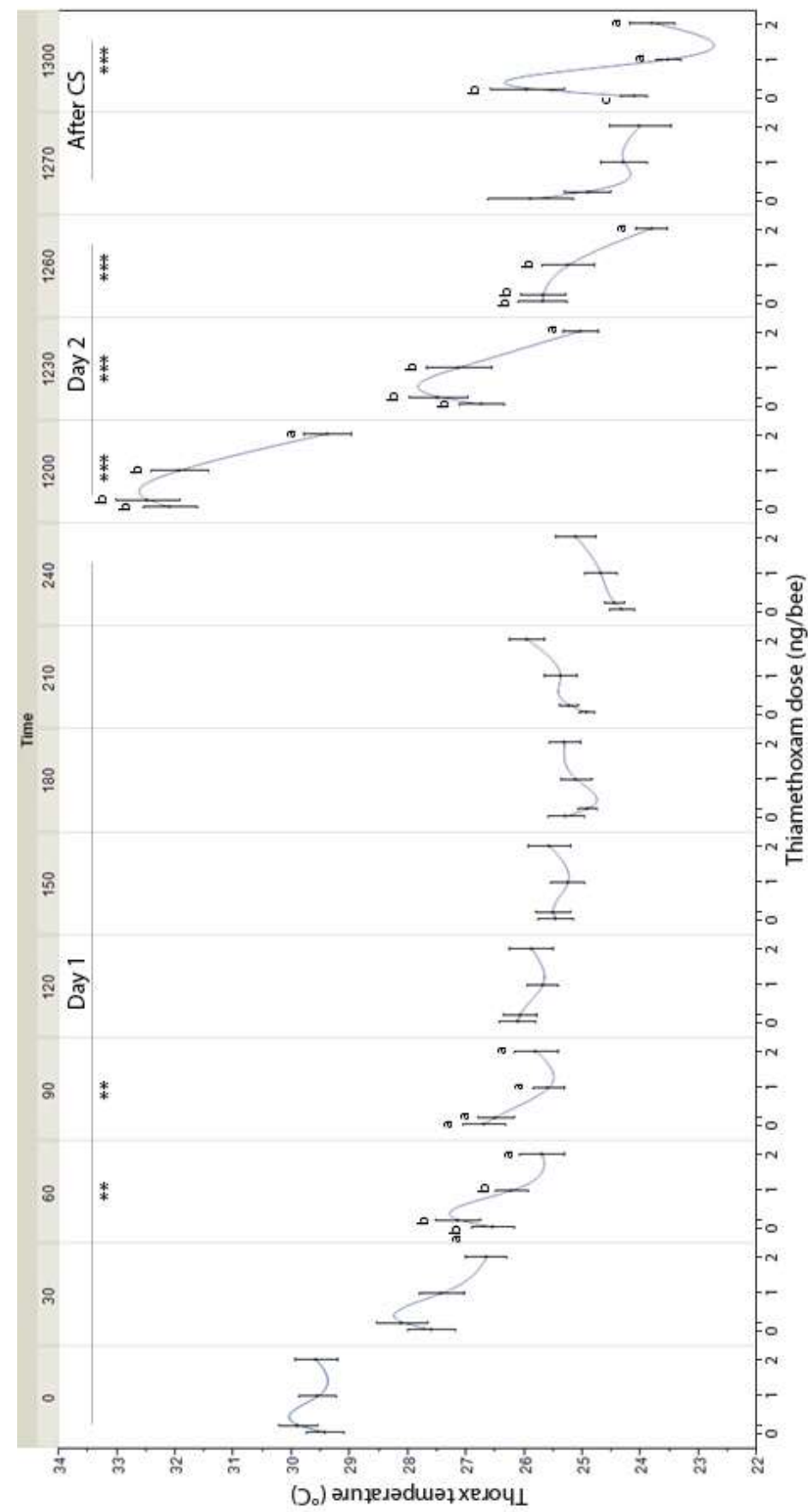

Figure S1. Mean thorax temperatures $( \pm \mathrm{SE})$ of harnessed forager honey bees after the acute exposure in Experiment 1 , in relation to the test dose assumed and the assessment time. The overall effect of dose $(0,0.2,1,2 \mathrm{ng} / \mathrm{bee}$, respectively control and low, medium and high dose of thiamethoxam) was statistically significant in each time period (Kruskal-Wallis Rank-Sum test at Day 1, Day 2 and After CS, respectively p=0.0008, p<0.0001, p<0.0001). Asterisks indicate statistically significant differences between doses within specific time recordings (Kruskal-Wallis Rank-Sum test, $* \mathrm{p}<0.05, * * \mathrm{p}<0.01$, *** $\mathrm{p}<0.001)$. Different letters indicate statistically significant differences between doses within specific time assessments (Wilcoxon paired test, $\mathrm{p}<0.0083$ after Bonferroni correction). Further post hoc comparisons are reported in Table 1. Time assessments shorter than $30 \mathrm{~min}$ intervals were excluded from the graphical representation to facilitate readability. 


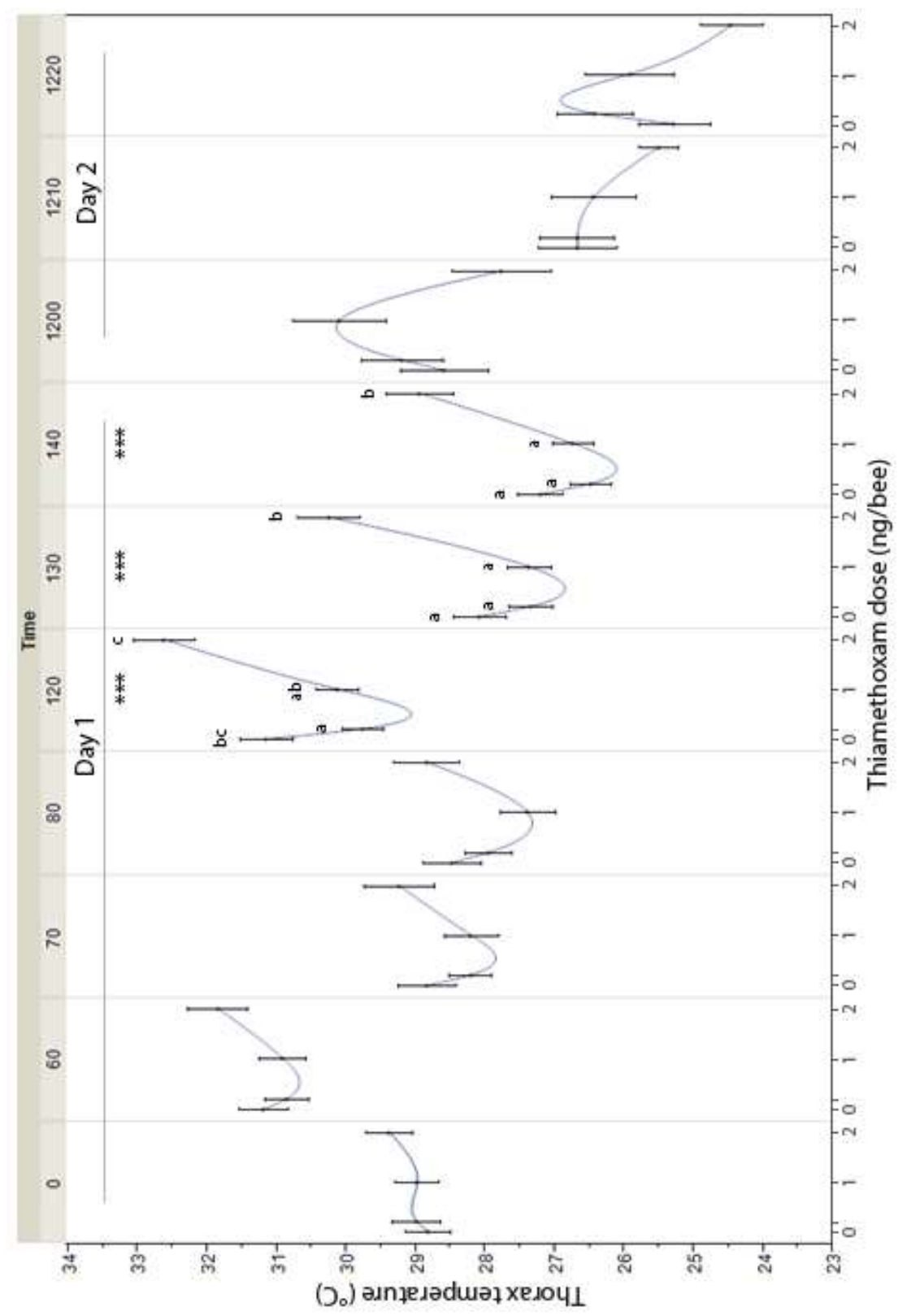

Figure S2. Mean thorax temperatures $( \pm \mathrm{SE})$ of harnessed forager honey bees after the acute exposure in Experiment 2, in relation to the test dose assumed and the assessment time. The effect of dose $(0,0.2,1,2$ $\mathrm{ng} / \mathrm{bee}$, respectively control and low, medium and high dose of thiamethoxam) was statistically significant during Day 1 (Kruskal-Wallis Rank-Sum test, p<0.0001). Asterisks indicate statistically significant differences between doses within specific time assessments (Kruskal-Wallis Rank-Sum test, * $\mathrm{p}<0.05$, ** $\mathrm{p}<0.01$, *** $\mathrm{p}<$ 0.001). Different letters indicate statistically significant differences between doses within specific time assessments (Wilcoxon paired test, $\mathrm{p}<0.0083$ after Bonferroni correction). Further post hoc comparisons are reported in Table 2. 


\begin{tabular}{|c|c|c|c|c|c|c|c|c|c|c|c|c|c|}
\hline \multirow{2}{*}{ Period } & \multirow{2}{*}{$\begin{array}{l}\text { Time } \\
(\min )\end{array}$} & \multicolumn{2}{|c|}{ ontrol vs Low } & \multicolumn{2}{|c|}{$\begin{array}{l}\text { Control vs } \\
\text { Medium }\end{array}$} & \multicolumn{2}{|c|}{ Control vs High } & \multicolumn{2}{|c|}{ Low vs Medium } & \multicolumn{2}{|c|}{ Low vs High } & \multicolumn{2}{|c|}{ Medium vs High } \\
\hline & & Z & F & Z & $P$ value & Z & Rulu & Z & & Z & & Z & lue \\
\hline \multirow{4}{*}{ Day 1} & & & & & & & & & & & & & \\
\hline & - & & 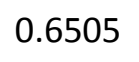 & .4148 & 1 & 6 & 1 & & & & & & 068 \\
\hline & 80 & 0.8148 & 0.4 & -0.9237 & 0.3557 & -2.2 & 0.0 & -1.8 & 79 & -3.0 & 23 & -0.5 & 0.3609 \\
\hline & $y$ & -0.12 & 0.8 & -2.3473 & 0.0 & -2.5 & & -2.2267 & & -2.3999 & & & 135 \\
\hline \multirow{5}{*}{ Day 2} & 1200 & 0.200 & & -0.46 & & -3.7 & & & & & & & \\
\hline & 1210 & -0.6717 & 0.50 & -1.2937 & 0.1 & -4.4 & 1 & -0.3 & 51 & -3 & 8 & & 15 \\
\hline & 1220 & -0.52 & & -1.1891 & 0.2 & $-4.6 \varepsilon$ & & & & & & & \\
\hline & 1230 & 0.47 & 0.63 & -0.5 & 0.5 & -3.56 & 4 & -0 & 1 & 30 & 4 & 38 & 04 \\
\hline & & 0.0861 & & & & -4.0716 & & -1.4210 & & -4 . & & -2 & 0.0080 \\
\hline Aft & 1290 & 0.5422 & 0.5877 & -3.0290 & 0.0025 & -3.3211 & 0.0 & -3.2800 & 10 & -3.4227 & 0.0006 & -0.3625 & 0.7170 \\
\hline 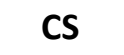 & 1300 & 2.2630 & 0.0236 & -3.3870 & 0.0007 & -3.0854 & 0.0020 & -4.2574 & $<.0001$ & -4.5928 & $<.0001$ & 0.1546 & 0.8772 \\
\hline
\end{tabular}

Table S1. Summary of the post hoc Wilcoxon paired test of Experiment 1. Post hoc tests were computed on time assessments that showed a main significant effect of treatment (control and low, medium and high doses of thiamethoxam, respectively $0,0.2,1,2 \mathrm{ng} / \mathrm{bee}$ ) (Kruskal-Wallis test). Statistically significant differences between doses within time assessments are reported in bold $(\mathrm{p}<0.0083$ after Bonferroni correction). 


\begin{tabular}{|c|c|c|c|c|c|c|c|c|c|c|c|c|c|}
\hline \multirow[t]{2}{*}{ Period } & \multirow{2}{*}{$\begin{array}{l}\text { Time } \\
(\min )\end{array}$} & \multicolumn{2}{|c|}{ Control vs Low } & \multicolumn{2}{|c|}{$\begin{array}{l}\text { Control vs } \\
\text { Medium }\end{array}$} & \multicolumn{2}{|c|}{ Control vs High } & \multicolumn{2}{|c|}{ Low vs Medium } & \multicolumn{2}{|c|}{ Low vs High } & \multicolumn{2}{|c|}{ Medium vs High } \\
\hline & & Z & ue & $\mathbf{Z}$ & $P$ value & z & $P$ value & Z & $P$ value & z & $P$ value & Z & $P$ value \\
\hline \multirow{3}{*}{ Day 1} & 120 & -2.7903 & 0.00 & -2.1855 & 0.0289 & 1371 & 0.0 & 0.6318 & 5 & 6535 & $<.0$ & .1577 & 0001 \\
\hline & 130 & -1.6073 & 0.1080 & -1.6663 & 0.0956 & 3.6685 & 0.0002 & -0.3115 & 0.7 & 5.0607 & $<.0001$ & 4.9625 & $<.0001$ \\
\hline & 140 & -2.0891 & 0.0367 & -1.1700 & 0.2420 & 2.5516 & 0.0107 & 1.1190 & 0.2632 & 4.3353 & $<.0001$ & 3.6307 & 0.0003 \\
\hline
\end{tabular}

Table S2. Summary of the post hoc Wilcoxon paired test of Experiment 2. Post hoc tests were computed on time assessments that showed a main significant effect of treatment (control and low, medium and high doses of thiamethoxam, respectively $0,0.2,1,2 \mathrm{ng} / \mathrm{bee}$ ) (Kruskal-Wallis test). Statistically significant differences between doses within time assessments are reported in bold $(\mathrm{p}<0.0083$ after Bonferroni correction) 